\title{
Extreme floods regionalisation in the tropical island of Tahiti, French Polynesia
}

\author{
Lucie Pheulpin $^{1, a}$, Alain Recking ${ }^{2}$, Lydie Sichoix ${ }^{1}$ and Jean-Pierre Barriot ${ }^{1}$ \\ ${ }^{1}$ GePaSud Laboratory, University of French Polynesia, 98702 Faa'a, Tahiti - French Polynesia \\ ${ }^{2}$ IRSTEA Grenoble, 2 rue de la Papeterie, 38402 Saint Martin d'Hères, France
}

\begin{abstract}
Flood hazards in the inactive volcanic island of Tahiti are very high. Indeed, the island is located in the South Pacific Ocean, in humid tropical climate and is exposed to cyclones. Even if the island is small $\left(1,042 \mathrm{~km}^{2}\right)$, rainfalls and runoffs are very different from one place to another. Precipitations are about 1,500 $\mathrm{mm} /$ year, and it rains twice as much on the East Coast than on the West Coast. Additionally, precipitations can reach $10 \mathrm{~m} / \mathrm{year}$ in the summits. Above all, catchments are small and elongated. These characteristics induce flash-floods which may cause heavy damages. In this study, data coming from 10 water-level gages are analysed by using a distribution function. After water level transformation to streamflow, the maximum annual runoffs are extracted and fitted according to a Gumbel law. For the 10 stations, the two Gumbel parameters are selected and used to establish a model of extreme runoff distribution, at the catchment outlets, for different return periods. This model depends on drainage area, annual precipitations, shape and position of the watersheds. It highlights that the valleys the most affected by floods are the bigger ones in the Northern and Eastern parts of the island, what we noted, for example, in December 2015.
\end{abstract}

\section{Introduction}

In the island of Tahiti, precipitations can be very high, especially during the wet season (November to April). They can reach several hundreds of millimetres in one day and are mainly influenced by topography and exposition to trade winds.

These extreme rainfalls can generate extreme runoffs which cause heavy damages. This happened in December 2015 in the North of Tahiti, where more than a hundred of houses have been damaged or totally destroyed.

There is no map of extreme runoffs in the island and only two studies have concerned surface hydrology in Tahiti [1,2]. Unfortunately, these studies focused on a handful of specific catchments.

This research aims to elaborate models and maps of extreme runoff distribution, at the outlets of the catchments, using time and space limited datasets.

\section{Study area and data}

The inactive volcanic island of Tahiti is located at the Southeastern end of the Society Archipelago, in the South Central Pacific Ocean. It is composed of two volcanoes, Tahiti-Nui, the main island and Tahiti-Iti, the peninsula. Both are linked by the Taravao Isthmus. The island is about $1,042 \mathrm{~km}^{2}$ and the summit (Mt. Orohena) is at 2,241 $\mathrm{m}$ high (Figure 1).

\footnotetext{
$\overline{{ }^{\mathrm{a}} \text { Corresponding author: lucie.pheulpin10@gmail.com }}$
}

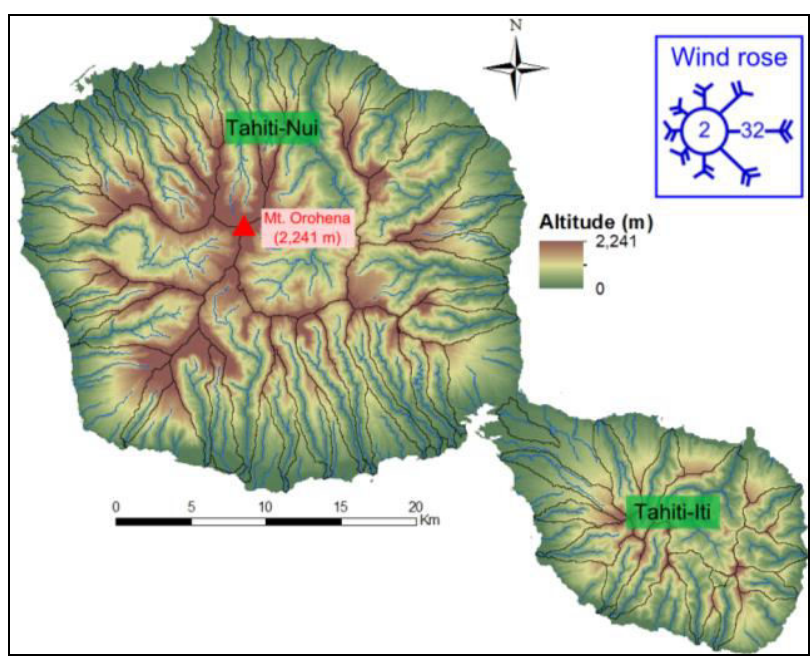

Figure 1: Tahiti Island

Tahiti is deeply dissected by erosion caused by the strong precipitations. They can reach $10 \mathrm{~m} /$ year in the summits and are very different from place to place. Because of the trade winds coming from the East of the island, it rains twice as much as on the East Coast than on the West Coast.

\subsection{Hydrological and meteorological data}

Ten water level gages are spread out over Tahiti and records cover a period from 12 to 40 years (Table 1 and Figure 2). 


\begin{tabular}{|c|c|c|c|c|}
\hline $\mathrm{N}^{\circ}$ & River & $\begin{array}{c}\text { Drainage area } \\
\left(\mathrm{km}^{2}\right)\end{array}$ & N. Year & $\begin{array}{c}\text { Qmax } \\
\left(\mathrm{m}^{3} / \mathrm{s}\right)\end{array}$ \\
\hline 1 & Faatahi & 0.6 & 12 & 2 \\
2 & Hitiaa & 1.6 & 23 & 35 \\
3 & Orofero & 18.6 & 26 & 23 \\
4 & Papeiha & 30.9 & 13 & 418 \\
5 & Papeivi & 1.3 & 12 & 5 \\
6 & Punaruu & 33.8 & 31 & 247 \\
7 & Tareta & 1.2 & 12 & 4 \\
8 & Tuauru & 25.7 & 40 & 149 \\
9 & Vaipahi & 1.1 & 14 & 4 \\
10 & Vairaharaha & 14.9 & 17 & 59 \\
\hline
\end{tabular}

Table 1: Features of the 10 water level gages in Tahiti-Nui.

Most of them are located at the outlets of catchments (Figure 2) and record the water level at about 15-minute intervals. After correcting dataset and establishing regular time-series, we converted water level data into runoff data. For this, we elaborated a rating curve for each instrumented river. This curve has been determined from monthly currentmeter gaugings. However, for big rivers, where we cannot use hydrometric currentmeter, we used a friction law (Ferguson 2007) to determine runoffs [3].

A general map of annual rainfall distribution, established by Lafforgue in 1993 [4], is also available and is shown in Figure 2.

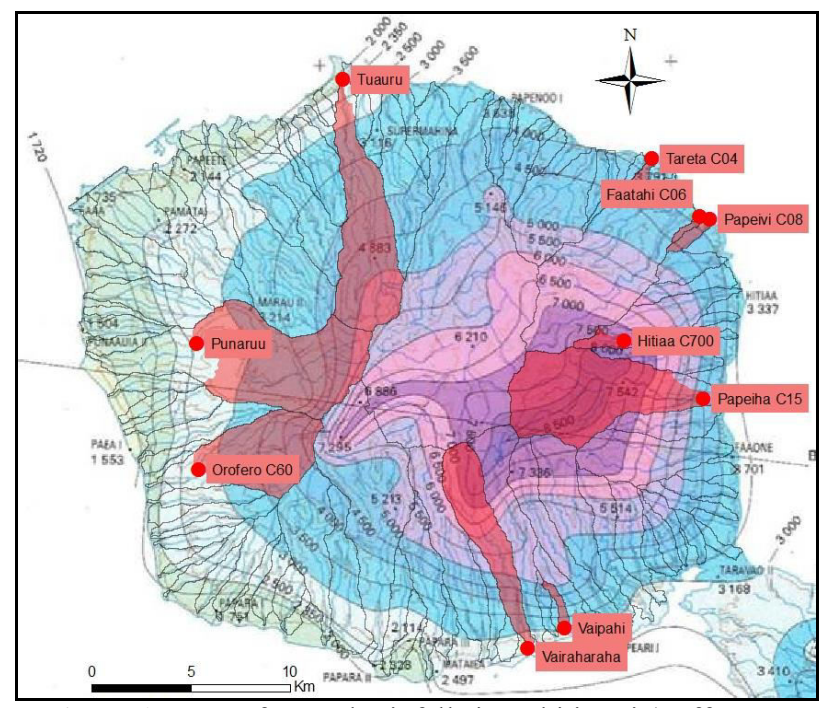

Figure 2: Map of annual rainfalls in Tahiti-Nui (Lafforgue, 1993). The red points are the water level gages and the red zones correspond to their drainage areas.

\subsection{Topographical data}

A 5-meter resolution DEM (Digital Elevation Model), for the whole island [5], allowed us to extract the main catchments of the island. Ninety-eight catchments extending over more than $1 \mathrm{~km}^{2}$ and 37 more than $5 \mathrm{~km}^{2}$ have been outlined.
Each watershed has been characterized by topographical parameters which are: perimeter, area, Gravelius coefficient, length of the catchment, azimuth, mean-slope, mean-altitude and maximum-altitude.

\section{Objectives and methods}

Our main objective is to establish a model of extreme runoffs at the catchment outlets, in function of topography and meteorological parameters. For this, from the 10 records described previously, we averaged runoffs over different time periods, from 15 minutes to 24 hours and we extracted, for each year, the maximum values. Here, only 2-hour averaged runoffs are presented.

To describe these extreme events, a Gumbel distribution function was used and the two parameters of the distribution were selected for each runoff record. Usually, the selected parameters are the gradex and the position parameter. The gradex is the slope of the fitting curve and it is linked to the intensity of extreme events; it increases with the rainfall intensity. The position parameter corresponds to the $\mathrm{Y}$-intercept. Here we did not extract the position parameter but the pivot point $(\mathrm{pv})$ which is the X-intercept of the fitted line. This point is also called "convergence point" because, for a given area and for same origin events, all the fitted lines of the Gumbel distributions functions converge towards this point [6].

Thus, maximum runoffs, recorded every year, have been plotted in function of the Gumbel variable and in function of the return period. The gradex and the pivot point have been extracted for each station (Figure 3).

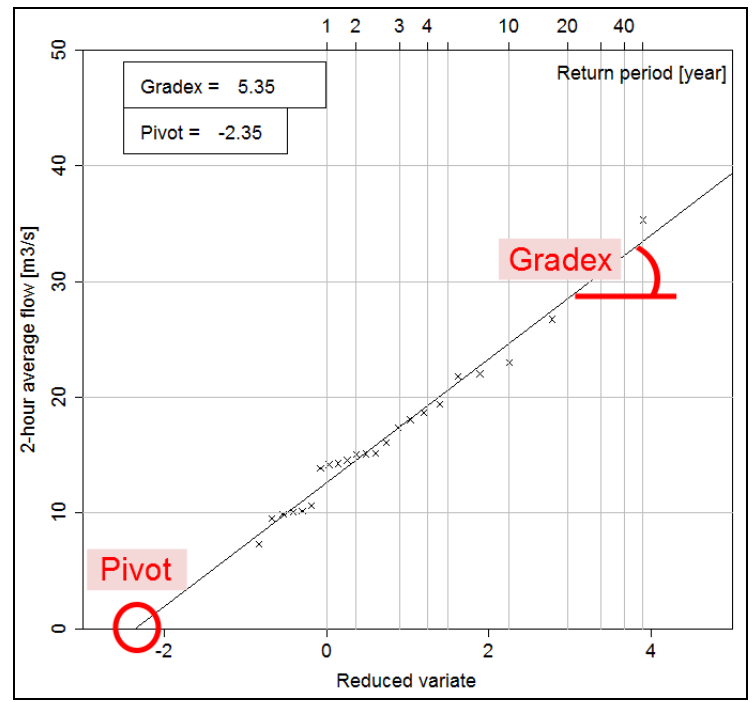

Figure 3: Distribution of extreme runoffs for the Hitiaa station

The gradex is the slope of the linear fit and the pivot is the intersection between the abscissa axis and the linear fit.

Our aim is to establish two different models based on 10 gauged catchments: one gradex model and one pivot model, depending on topographical environment. By combining these two models, we are able to predict extreme runoffs for ungauged catchments and map runoffs, with different return periods. 
All instrumented catchments were then characterized by key parameters. A lot of combinations have been tested to elaborate the best runoff model and finally only four parameters were selected to explain gradex and pivot. They are:

- $\quad$ Area of the watershed $\left(\mathrm{km}^{2}\right)$

- Annual maximum precipitations extracted from the map in Figure 2 ( $\mathrm{mm})$

- Azimuth, which is the angle between the North and the main direction of the catchment $\left(^{\circ}\right)$

- Gravelius coefficient, which is a shape factor $\left(0.28 \mathrm{P} / \mathrm{A}^{1 / 2}\right)$

Table 2 contains gradex, pivot and parameters described previously, for each station. Four catchments are very small and have similar characteristics (Faatahi, Papeivi, Tareta and Vaipahi). The Hitiaa catchment is, in fact, much bigger $\left(10 \mathrm{~km}^{2}\right)$, but the water level gauge is at an altitude of $700 \mathrm{~m}$ and the drainage area is only 1.6 $\mathrm{km}^{2}$. The largest instrumented catchment is the one of Punaruu River $\left(33.8 \mathrm{~km}^{2}\right)$. There is only one larger watershed, the Papenoo valley, in the North of the island $\left(90 \mathrm{~km}^{2}\right)$. It is almost 3 times larger than the Punaruu valley. This is why our model, described thereafter, may be unreliable for this catchment.

\begin{tabular}{|c|c|c|c|c|c|c|c|}
\hline $\mathrm{N}^{\circ}$ & River & $\begin{array}{c}\text { Drainage } \\
\text { area }\left(\mathrm{km}^{2}\right)\end{array}$ & $\mathrm{Kc}$ & $\begin{array}{c}\text { Azimut } \\
\left({ }^{\circ}\right)\end{array}$ & $\begin{array}{c}\text { Annual } \\
\text { Precipitation } \\
(\mathrm{mm})\end{array}$ & Gradex & Pivot \\
\hline 1 & Faatahi & 0.6 & 2.37 & 59 & 4500 & 0.36 & -2.49 \\
2 & Hitiaa & 1.6 & 2.17 & 76 & 8000 & 5.35 & -2.35 \\
3 & Orofero & 18.6 & 1.77 & 248 & 5000 & 4.56 & -1.37 \\
4 & Papeiha & 30.9 & 1.72 & 96 & 8500 & 74.65 & -2.65 \\
5 & Papeivi & 1.3 & 2.06 & 63 & 4500 & 0.78 & -3.91 \\
6 & Punaruu & 33.8 & 2.02 & 275 & 5500 & 51.4 & -1.4 \\
7 & Tareta & 1.2 & 1.98 & 45 & 4000 & 0.65 & -3.17 \\
8 & Tuauru & 25.7 & 2.2 & 346 & 5500 & 25.55 & -2.36 \\
9 & Vaipahi & 1.1 & 2.24 & 150 & 5000 & 0.66 & -1.54 \\
10 & Vairaharaha & 14.9 & 2.31 & 159 & 8000 & 11.51 & -2.02 \\
\hline
\end{tabular}

Table 2: Topographical, meteorological and Gumbel parameters for each instrumented catchment.

Gravelius coefficient, also called compactness coefficient $(\mathrm{Kc})$ ranges from 1.77 to 2.37 and describes the watershed elongation. It is the ratio between the catchment perimeter and the circumference of a circle with the same area. Kc is always greater than 1 and is close to 1 when the basin approaches a circular shape. It is important to take it into account because the response at the outlet can be very different between circular and elongated catchments.

As the trade winds mainly affect the East Coast, rainfalls and runoffs are obviously higher in this zone, hence the significance of the azimuth as a parameter.

Annual precipitation can be twice higher from a catchment to another, so this is an essential parameter in our model.

\section{Results}

We tried to elaborate extreme runoff models depending on the parameters presented previously and for different time periods. To achieve this, we first built one gradex model and one pivot model thanks to the 10 runoff records coming from the 10 water level gages spanning the island.

\subsection{Gradex model}

Correlation matrix analysis allowed us to elaborate the best-gradex model which only depends on the drainage area $(A)$ and annual rainfall $(P)$ :

$$
G d=1.4655 A+0.0036 P-22.5414
$$

The fitting coefficients are $78 \%$ for the $\mathrm{R}^{2}$ and $72 \%$ for the adjusted- $\mathrm{R}^{2}$. P-value is about 0.005 . The catchment area is the parameter which has the main influence on the gradex. The Figure 4 shows the quality of the adjustment.

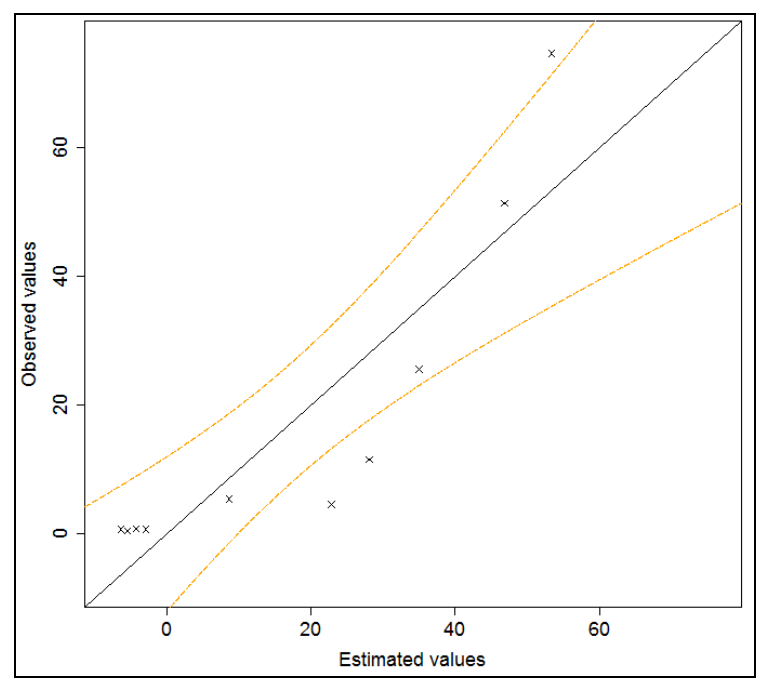

Figure 4: Gradex model adjustment in function of area and annual precipitation. The orange dotted line corresponds to the confidence interval of $95 \%$.

We extrapolated this model to the other catchments. Figure 5 shows that the catchment area has a main influence on the gradex, the gradex being higher on the biggest valleys of the island. The main drawback is that the model does not work for the small catchments $\quad(<5$ $\mathrm{km}^{2}$ ), in fact the gradex is equal to zero or is negative for these basins. 


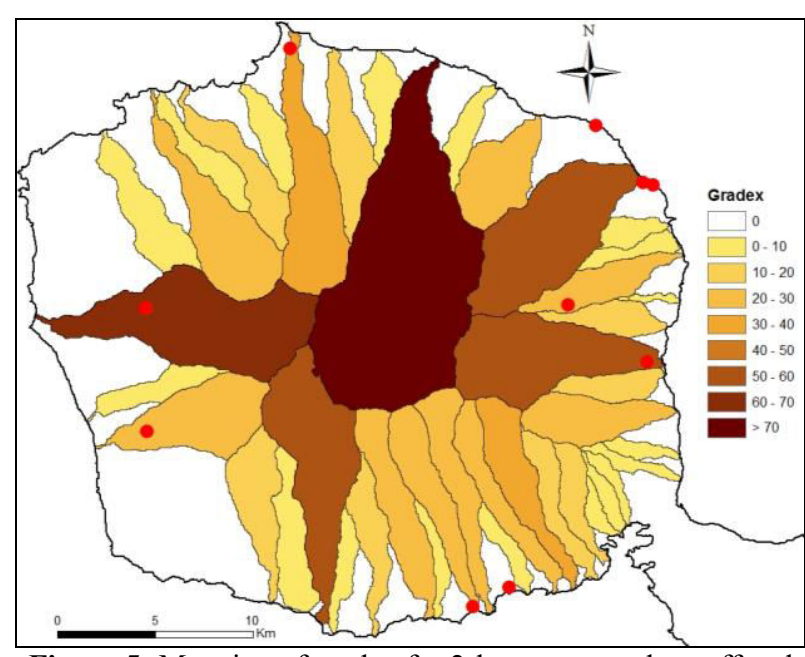

Figure 5: Mapping of gradex for 2-hour averaged runoff and for catchments larger than $5 \mathrm{~km}^{2}$.

For other watersheds, gradex is between 0.4 and 137. The minimum corresponds to a small catchment in the Western part of the island and the maximum corresponds to the large Papenoo valley. But, as the maximum measured gradex is the one from the Papeiha valley (75), care about using our model should be taken for larger catchments. Besides, the Papenoo valley hosts hydroelectric dams, retaining the water, so flow in the outlet is necessarily lower than the one calculated.

\subsection{Pivot model}

Using the same method than previously (paragraph 4.1), a pivot model was produced. It depends on three parameters which are the azimut $(\alpha)$, the Gravelius coefficient $(K c)$ and the annual rainfall $(P)$ :

$$
P v=-0.8698 \sin (\alpha)+0.9370 K c+0.0002 P-5.0507
$$

Results are poorer than for the gradex model. The $\mathrm{R}^{2}$, the adjusted $\mathrm{R}^{2}$ and the $\mathrm{P}$-value are respectively $63 \%$, $44 \%$ and 0.095 . The pivot values range from about -3.8 to -1.3 for observed and estimated values. The station the most distant to the model are not necessarily the ones with a small drainage area, which is the opposite from the gradex model (Figure 6).

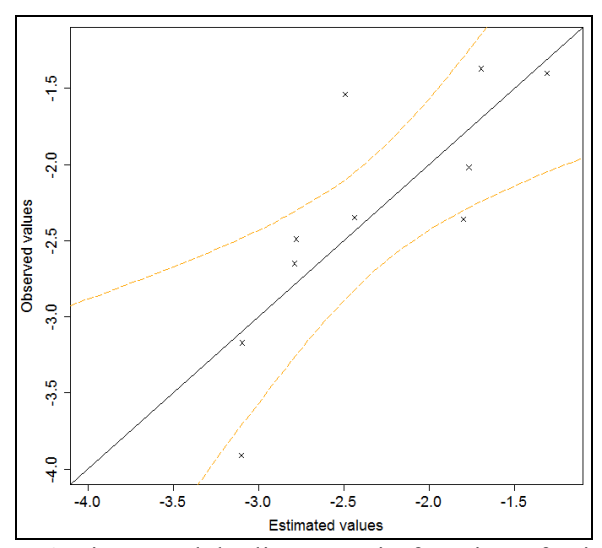

Figure 6: Pivot model adjustment in function of azimuth, Gravelius coefficient and annual precipitation. The orange dotted line corresponds to the confidence interval of $95 \%$.
This pivot model was also extrapolated to other catchments. On Figure 7, it is obvious that the pivot mainly depends on azimuth. It is lower on the Northern and Eastern part of the island than on the opposite. The pivot also seems to be higher for elongated watershed than for more circular ones

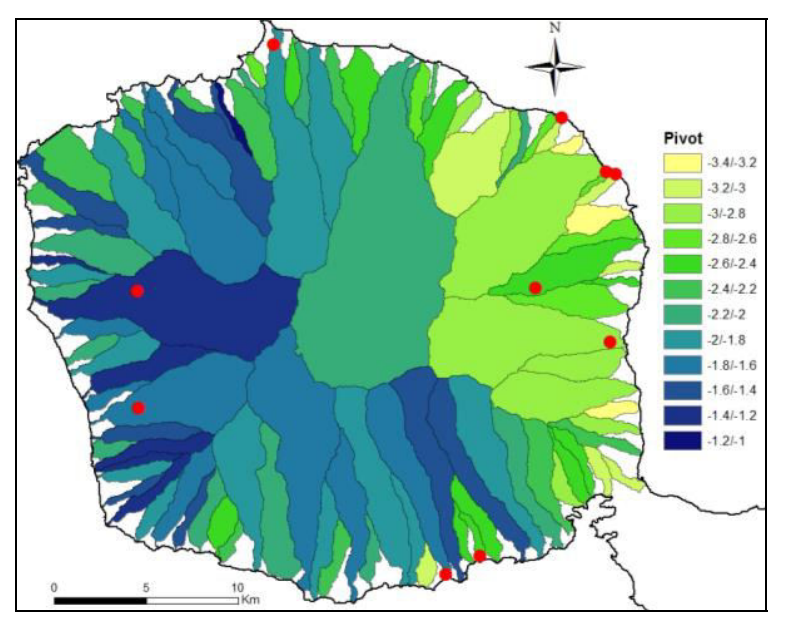

Figure 7: Mapping of pivot for 2-hour averaged runoff and for catchments larger than $1 \mathrm{~km}^{2}$.

This map (Figure 7) is available for catchments larger than $1 \mathrm{~km}^{2}$. Pivot related to it ranges from -3.4 to 1.2 .

\subsection{Mapping of extreme flows}

Thanks to the gradex and pivot models, maps with different return periods have been established. Maximum runoff with a 10-year return period (Figure 8) is about $300 \mathrm{~m}^{3} / \mathrm{s}$ and concerns the Tefaarahi River (in the NorthEast of the island), excluding the largest valley of the Papenoo.

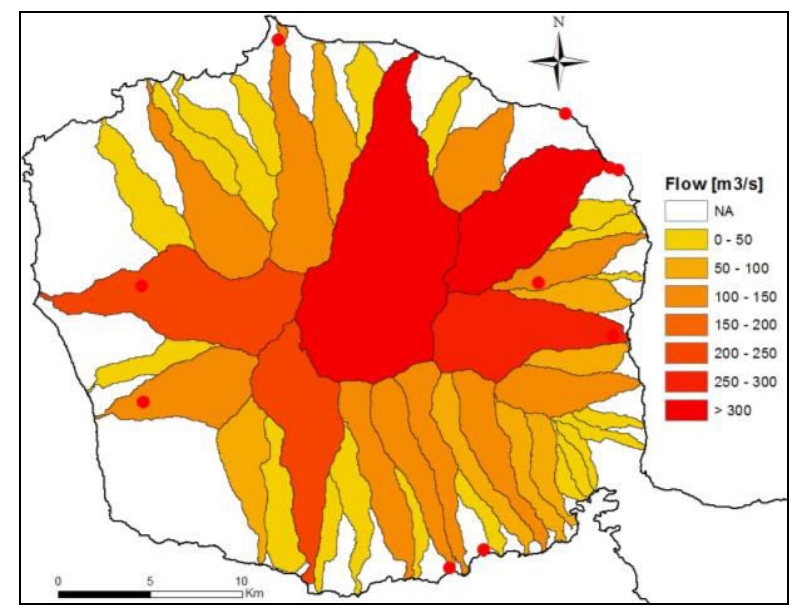

Figure 8: Mapping of 2-hour averaged flow for a return period of 10 years and only for catchments larger than $5 \mathrm{~km}^{2}$.

For a 50-year return period (Figure 9), runoff in the Tefaarahi River can reach $400 \mathrm{~m}^{3} / \mathrm{s}$. In general, major floods occur in the North and East Coast and obviously in large catchments. They are less important in elongated basins. 


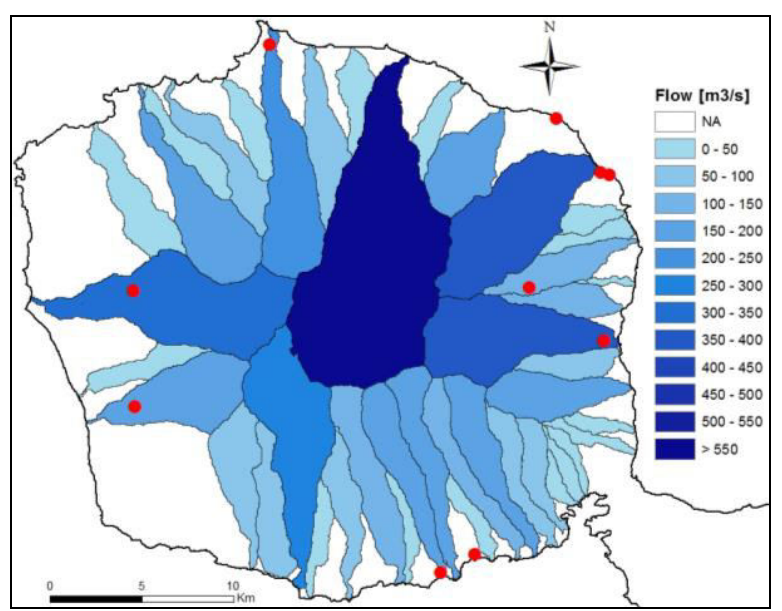

Figure 9: Mapping of 2-hour averaged flow for a return period of 50 years and only for catchments larger than $5 \mathrm{~km}^{2}$.

\section{Validation and discussion}

\subsection{Validation by removing stations}

The outlined model is made from all the available data. However, to validate a model, it should be compared with independent data, which suppose to split the dataset between one part used for the model construction and a second part used for the validation.

Albeit the datasets at our disposal are very limited, we tried to delete records one by one and to elaborate models without them. Once established, we calculated the difference between the observed and estimated values. We did it for the gradex and pivot models (Table 3 and Table 4).

Once again, the results obtained for small catchments are problematic. Differences between observed and calculated gradex are very high. For the other watersheds, the differences are also large, so we took into account all ranges of catchment area. Removing a station from the model construction can lead to very different coefficients.

\begin{tabular}{|c|c|c|c|c|}
\hline $\mathrm{N}^{\circ}$ & River & Gd-Obs & Gd-Est & $\Delta[\%]$ \\
1 & Faatahi & 0.36 & -7.14 & -105 \\
2 & Hitiaa & 5.35 & 11.95 & 55 \\
3 & Orofero & 4.56 & 26.7 & 83 \\
4 & Papeiha & 74.65 & 35.93 & 108 \\
5 & Papeivi & 0.78 & -5.74 & -114 \\
6 & Punaruu & 51.4 & 43.24 & 19 \\
7 & Tareta & 0.65 & -8.96 & -107 \\
8 & Tuauru & 25.55 & 37.93 & 33 \\
9 & Vaipahi & 0.66 & -3.81 & -117 \\
10 & Vairaharaha & 11.51 & 35.15 & 67 \\
\hline
\end{tabular}

Table 3: Difference between observed and estimated gradex. Rivers in the $2^{\text {nd }}$ column are the rivers deleted from the model.

As the pivot does not depend on area, there is no problem with the small catchments. The minimum obtained difference is for the Tareta River which is one of the smallest studied watersheds and the maximum is for the Vaipahi River (equal to Tuauru River) which is also a small catchment. If we remove one station, the coefficients of the model equation remain almost the same.

\begin{tabular}{|c|c|c|c|c|}
\hline$N^{\circ}$ & River & Pv-Obs & Pv-Est & $\Delta[\%]$ \\
\hline 1 & Faatahi & -2.49 & -2.96 & -16 \\
2 & Hitiaa & -2.35 & -2.48 & -5 \\
3 & Orofero & -1.37 & -2.07 & -34 \\
4 & Papeiha & -2.65 & -3.2 & -17 \\
5 & Papeivi & -3.91 & -2.75 & -42 \\
6 & Punaruu & -1.4 & -1.24 & -13 \\
7 & Tareta & -3.17 & -3.05 & -4 \\
8 & Tuauru & -2.36 & -1.65 & -43 \\
9 & Vaipahi & -1.54 & -2.71 & -43 \\
10 & Vairaharaha & -2.02 & -1.54 & -32 \\
\hline
\end{tabular}

Table 4: Difference between observed and estimated pivot. Rivers in the $2^{\text {nd }}$ column are the rivers deleted from the model.

\subsection{Comparison with other studies}

As mentioned in part 1, only two studies on extreme flood events have been done in Tahiti. We looked for extreme events described in these works to compare them with our model.

Wotling (2000) focused on three small catchments, which cannot be used for comparisons because they are too small, and one larger catchment, called Titaaviri (Figure 10). During the cyclonic season of 1997-1998, the runoff of Titaaviri River reached $300 \mathrm{~m}^{3} / \mathrm{s}$. This major flood was evaluated as a 50-year return period flood. From our model, the runoff for this river, for the same return period, is $220 \mathrm{~m}^{3} / \mathrm{s}$. The gap between both is more than $30 \%$, but $300 \mathrm{~m}^{3} / \mathrm{s}$ corresponds to the peak flow while in our case it is the 15 -minute averaged flow. The peak flow is necessary higher. As our model was elaborated from 20 years of data on average, it is then unreliable with respect to long return periods.

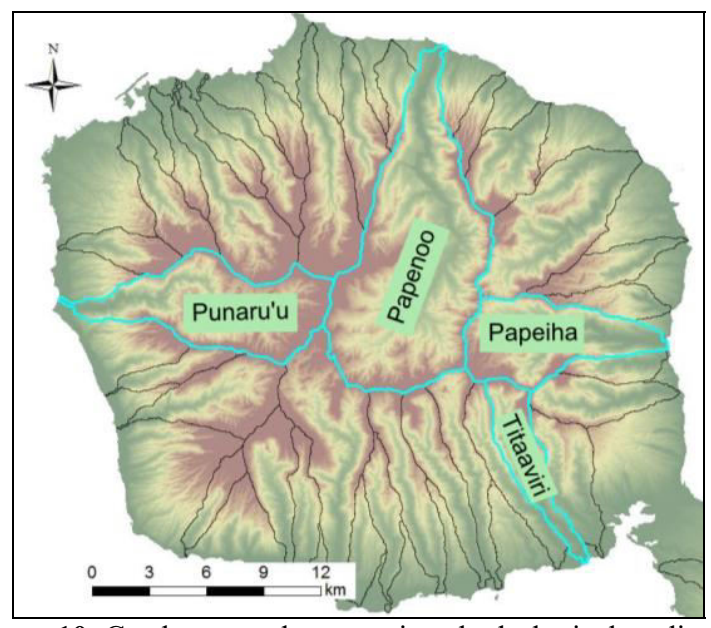

Figure 10: Catchments where previous hydrological studies have been ever made 
Ferry (1988) studied the cyclonic season of 19821983 which was one of the worst in the past 100 years. He estimated extreme runoff values for the Punaruu, Papeiha and Papenoo rivers (Figure 10). For the Papenoo catchment, we cannot test our model with Ferry's data because dams were constructed in the eighties. Regarding the Punaruu River, Ferry estimated a runoff of $260 \mathrm{~m}^{3} / \mathrm{s}$ with a 10-year return period, which is exactly the value given by our model. However, for a 50-year return period, Ferry estimated a runoff of $480 \mathrm{~m}^{3} / \mathrm{s}$, against $380 \mathrm{~m}^{3} / \mathrm{s}$ for our model. For the Papeiha River, gaps between Ferry data and our models are higher, probably because only 13 years of data are available for the Papeiha station and the two main cyclonic periods (82-83 and 98-99) are not taken into account. Our model provided a runoff value of $400 \mathrm{~m}^{3} / \mathrm{s}$ while Ferry estimated $600 \mathrm{~m}^{3} / \mathrm{s}$ for a 10 -year return period and differences are much higher for the 50-year return period (Table 5).

All these comparisons indicate that our model gives realistic results. Additional data are needed for improving prediction for high return periods. Unfortunately, Ferry and Wotling recorded data during short time periods and times series are not regular. This means that we cannot use them in our model.

\begin{tabular}{|c|c|c|c|c|}
\cline { 2 - 5 } \multicolumn{1}{c|}{} & $\begin{array}{c}\text { Return } \\
\text { period } \\
{[\mathrm{y}]}\end{array}$ & $\begin{array}{c}\text { Runoff } \\
\text { from our } \\
\text { model } \\
{\left[\mathrm{m}^{3} / \mathrm{s}\right]}\end{array}$ & $\begin{array}{c}\text { Runoff } \\
\text { estimated } \\
\text { by Ferry } \\
{\left[\mathrm{m}^{3} / \mathrm{s}\right]}\end{array}$ & $\begin{array}{c}\Delta \\
{[\%]}\end{array}$ \\
\hline \multirow{3}{*}{ Punaruu } & 10 & 260 & 260 & 0 \\
\cline { 2 - 5 } & 50 & 380 & 480 & 26 \\
\hline \multirow{3}{*}{ Papeiha } & 10 & 400 & 600 & 50 \\
\cline { 2 - 5 } & 50 & 500 & 1000 & 100 \\
\hline
\end{tabular}

Table 5: Comparison between runoffs deduced from our model and runoffs estimated by Ferry.

\subsection{Models elaborated on different time periods}

As mentioned previously, we also established models for different durations (15 minutes, 30 minutes, 1 hour, 6 hours, 12 hours and 24 hours). Models elaborated for durations exceeding 2 hours, have the same parameters than the one described in paragraph 4 , and coefficients of determination and validation tests are very similar. These models are not very useful because in Tahiti, catchments are small and elongated, inducing flash-floods which are strong but of very short duration.

For the other models (over 15 minutes, 30 minutes and 1 hour), the parameterization slightly differs from the previous ones. To calculate the gradex, we did not only use the area and the annual rainfall but also the compactness coefficient (Kc). Regarding the pivot, the best models depend on azimuth, annual rainfall and mean-altitude (instead of $\mathrm{Kc}$ in the previous pivot model). It does not change so much because the gradex is also mainly influenced by area and the pivot by the azimuth. Obviously gradex are higher and pivot are different but rivers with a high gradex or a high pivot are still the same.
The main problems arising in these models are data gaps (mainly at the beginning of the data acquisition), thus these models can be underestimated. Mapping of 15minute flows is similar to the 2-hour mapping (Figure 8) with the same colour scale. Runoff values at the outlet of the catchments are slightly higher. We compare, in Table 6, flows for different valleys and over different time periods. For example, for the Tuauru River, runoff is the same regardless of the considered time period.

\begin{tabular}{|c|c|c|c|c|}
\hline River & $15 \mathrm{~min}$ & $30 \mathrm{~min}$ & $1 \mathrm{~h}$ & $2 \mathrm{~h}$ \\
\hline Tefaarahi & 407 & 390 & 350 & 300 \\
Papeiha & 391 & 373 & 338 & 280 \\
Titaaviri & 163 & 154 & 139 & 127 \\
Punaruu & 262 & 255 & 235 & 219 \\
Tuauru & 161 & 159 & 150 & 148 \\
\hline
\end{tabular}

Table 6: Runoffs $\left[\mathrm{m}^{3} / \mathrm{s}\right.$ ] averaged over different time periods, at the outlet of 5 catchments, for a 10 -year return period.

\subsection{Sources of uncertainties and possible improvements}

Sources of errors in our model are numerous. First, as we have no measurements for high flow conditions, the rating curves are uncertain for extreme events. Other gauging methods must be used to improve these rating curves.

Second, for stations for which we have only a small dataset, it is hard to fit extreme events on a Gumbel graph. The only solution is to continue to collect data for several years to capture a sufficient number of extreme events and to improve the Gumbel fits. Overall, with more data, we could define precisely 50 -year or 100 -year floods.

Third, the spatial repartition of data points is strongly unequal. As shown in the previous map (Figure 2), there are no instrumented catchments in the NW, SE and SW parts of the island. We need a better distributed network of instrumented catchments, and it is necessary to have instruments in a large range of drainage area sizes.

Finally, a major problem concerns the rivers crossed by dams. In Tahiti, there are 15 hydroelectric dams spread over 5 valleys (Figure 11). The reservoir volumes range from 10,000 to $870,000 \mathrm{~m}^{3}$. There is also a natural lake called Vaihiria 3 with a capacity of $3,980,000 \mathrm{~m}^{3}$. At the beginning of the floods, dams retain a part of the water thus, runoffs calculated at the outlet of these valleys are overestimated because the model does not consider dams. For the Titaaviri, Vaite and Faatautia valleys, dams are relatively small and during extreme events they quickly overflow, therefore, the model overestimate a very few the runoffs. For the Vaihiria valley, where there are 2 dams and one natural lake, and for the Papenoo valley, which is the biggest one, the runoffs are much more overestimated. Similarly, in the Punaruu River, there is a pumping station downstream of the water level gauge, thus, when the pumping is done, runoffs at the outlet are biased. 


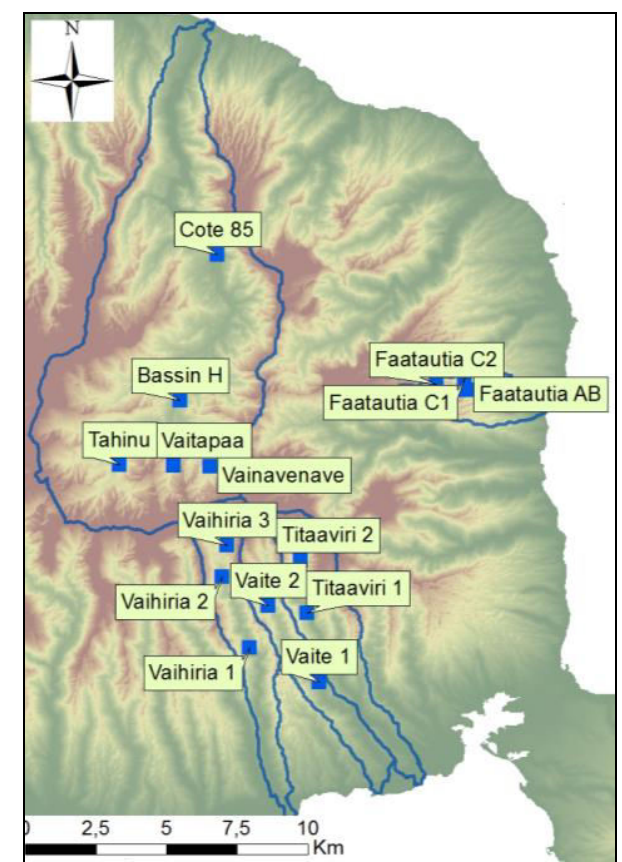

Figure 11: Hydroelectric dams in Tahiti. 5 are in the Papenoo valley, 3 in Vaihiria, 3 in Faatautia, 2 in Vaite and 2 in Titaaviri.

\section{Conclusion}

With 10 water level gages, having recorded 20 years of data on average, and one DEM, extreme runoff maps were established for the Tahiti Island. They result from a combination of gradex maps and pivots maps, the two parameters of the Gumbel distribution function describing the extreme events. The gradex gives information about the event intensities and increases with drainage area and annual rainfalls. The pivot is linked to the event frequency and it is inversely proportional to the number of events. It decreases with the azimuth, which means that the valleys on the Eastern Coast have a lower pivot, thus a larger number of events, than the valleys on the Western Coast. Moreover, the pivot increases with the Gravelius coefficient and the annual rainfall.

The extreme runoff maps show that the valleys the most affected by floods are the largest ones in the Northern and Eastern part of the island. Precipitations are more intense and more numerous in these zones.

We proposed extreme flow values with different return periods for the main rivers of the island. The results are questionable for the following reasons:

- We used runoffs recorded by 10 water level gages only, to predict runoffs of more than 40 rivers. The measurement network must be developed to obtain more precise models.

- The records cover a period of 20 years on average, which is too short to predict realistic runoffs for return periods of 50 years.

- Five valleys contain dams, 2 with 3 or more big dams, retaining water and our model does not consider the water reservoirs. Runoffs of these valleys are probably overestimated.

\section{References}

1. Ferry L. (1988). Contribution à l'étude des régimes hydrologiques de l'île de Tahiti. Thèse de doctorat, Université Paris-Sud, 164 pp.

2. Wotling G. (1999). Caractérisation et modélisation de l'aléa hydrologique à Tahiti. Thèse de doctorat, Université Montpellier 2, 308pp.

3. Ferguson R. (2007). Flow resistance equations for gravel and boulder bed streams. Water Resources Research, Vol. 43, W05427.

4. Lafforgue A. (1993). La climatologie des îles, Atlas de la Polynésie française, Edition de l'ORSTOM, pp. 112.

5. DEM available at the "Service de l'Urbanisme de la Polynésie Française". (2003). (http://www.urbanisme.gov.pf/).

6. Meunier M. (2001). Regional flow-durationfrequency model for the tropical island of Martinique. Journal of hydrology, Vol 247, pp 31-53. 